Check for updates

Cite this: RSC Adv., 2018, 8, 21326

Received 1st April 2018

Accepted 30th May 2018

DOI: 10.1039/c8ra02806k

rsc.li/rsc-advances

\title{
Template-free synthesis of monolithic carbon xerogels with hierarchical porosity from resorcinol and formaldehyde via hydrothermal reaction $\uparrow$
}

\author{
G. Cho, J. Y. Lee (D) and T. H. Yoon (D)*
}

\begin{abstract}
Monolithic carbon xerogels with hierarchical porosity were prepared from resorcinol (R) and formaldehyde (F) via a base-catalysed hydrothermal polycondensation reaction, without a template and supercritical drying. First, an aqueous solution of resorcinol, formaldehyde and sodium carbonate was prepared by varying R/W (25-45) and R/C (1-10k) ratios to produce monolithic RF gels. The reaction was carried out in a pressurized Teflon mould at $100{ }^{\circ} \mathrm{C}$ for $6 \mathrm{~h}$ to give a co-continuous pore structure via spinodal decomposition and a tenacious gel to avoid supercritical drying. Next, the RF gels were dried for $42 \mathrm{~h}$ at $60{ }^{\circ} \mathrm{C}$ and another $6 \mathrm{~h}$ at $100{ }^{\circ} \mathrm{C}$ to produce RF xerogels without cracks, followed by pyrolysis in a tube furnace at $900{ }^{\circ} \mathrm{C}$ for $2 \mathrm{~h}$ under $\mathrm{N}_{2}$ flow, and then activation at $1000{ }^{\circ} \mathrm{C}$ for 2,4 or $6 \mathrm{~h}$ under $\mathrm{CO}_{2}$ flow. Finally, the carbon xerogels were characterized by SEM and $\mathrm{N}_{2}$ adsorption-desorption measurements. Monolithic RF gels were obtained from all combinations of R/W and R/C, but the gels from R/W $=45$ exhibited a co-continuous large-pore structure, providing a specific surface area (SSA) of $\sim 650 \mathrm{~m}^{2} \mathrm{~g}^{-1}$, which increased to $3311 \mathrm{~m}^{2} \mathrm{~g}^{-1}$ (for $\mathrm{R} / \mathrm{C}=10 \mathrm{k}$ ) at $6 \mathrm{~h}$ of $\mathrm{CO}_{2}$ activation without exhibiting cracks. $\mathrm{N}_{2}$ isotherms demonstrated that micro- and meso-pores were introduced via activation, forming hierarchical porosity in combination with large pores from spinodal decomposition without using a template.
\end{abstract}

\section{Introduction}

Ever since Pekala introduced the base-catalysed polycondensation reaction of resorcinol-formaldehyde, ${ }^{1}$ it has been widely studied for the preparation of porous carbon materials (PCM) of particulates, ${ }^{2}$ as well as monoliths, ${ }^{3-7}$ with the latter being preferred due to easy handling. ${ }^{\mathbf{8} 9}$ The recent applications of PCM in electrodes for capacitors, batteries or fuel cells, ${ }^{\mathbf{1 0}}$ catalyst supports ${ }^{\mathbf{1 1}}$ carbon dioxide capture ${ }^{\mathbf{1 2}}$ and water purification ${ }^{\mathbf{1 3 , 1 4}}$ have led to the desirability of hierarchical porosity for higher performance. ${ }^{15}$ This can be achieved by forming not only micro- and meso-pores for a high specific surface area (SSA), and thus, high adsorption, but also macro-pores for higher flow efficiency. ${ }^{\mathbf{1 6}}$

School of Materials Science and Engineering, Gwangju Institute of Science and Technology (GIST), 123 Cheomdan-gwagiro (Oryong-dong), Buk-gu, Gwangju 61005, Republic of Korea. E-mail: thyoon@gist.ac.kr

$\dagger$ Electronic supplementary information (ESI) available: Photo of monolithic RF (left) and carbon (right) xerogels. TGA of monolithic carbon xerogels of $45-10 \mathrm{k}$ under $\mathrm{N}_{2}$ flow at $10{ }^{\circ} \mathrm{C} \mathrm{min}^{-1}$. SEM micrographs from monolithic carbon xerogels of (a) $35-1 \mathrm{k}$, (b) $35-2.5 \mathrm{k}$, (c) $35-5 \mathrm{k}$, and (d) $35-10 \mathrm{k}$. SEM micrographs from monolithic carbon xerogels of (a) 25-1k, (b) 25-2.5k, (c) 25-5k, and (d) 25-10k. Nitrogen isotherms (a) and pore size distribution (b) of monolithic carbon xerogels of 45-2.5k upon 2,4 , or $6 \mathrm{~h}$ activation. Burn off ratio (\%) of monolithic carbon xerogels from $\mathrm{R} / \mathrm{W}=45$ upon activation. Crack generation of monolithic carbon xerogels from $\mathrm{R} / \mathrm{W}=45$ upon activation. Characteristics of monolithic carbon xerogels of $45-2.5 \mathrm{k}$ upon activation. See DOI: $10.1039 / \mathrm{c} 8 \mathrm{ra} 02806 \mathrm{k}$
Consequently, a great deal of research has reported the successful preparation of hierarchical porosity via hard-soft templates, ${ }^{17-19}$ soft-soft templates, ${ }^{20}$ special solvents or additives, ${ }^{21,22}$ and polymerization-induced spinodal decomposition with soft templates ${ }^{23-25}$ or self-assembly. ${ }^{26}$ Of these, the last approach seems to be simpler than the others due to the onestep aqueous solution reaction of $\mathrm{RF}$ with only soft templates. ${ }^{15}$ However, spinodal decomposition provided aggregation of particles, in general, generating small pores between them, rather than co-continuous pore structure via interconnection of particles, while the latter is preferred for better performance. Of course, it was successfully achieved from solgel process ${ }^{27}$ as well as from some other polymers. ${ }^{28,29}$ Moreover, this approach generally requires supercritical or freeze drying to retain the pore structure, ${ }^{2-6}$ making the PCM expensive.

Recently, Huang and co-workers reported the successful preparation of monolithic PCM with hierarchical porosity from phenolformaldehyde without supercritical drying. ${ }^{30}$ They reported a cocontinuous large pore $(10-20 \mu \mathrm{m})$ structure with interconnected particles via polymerization-induced spinodal decomposition, which is possibly due to hydrothermal reaction. The hydrothermal reaction is also believed to generate a tenacious polymer network to make supercritical drying unnecessary, and thus, providing xerogels. However, its specific surface area (SSA) remained low $\left(\sim 620 \mathrm{~m}^{2} \mathrm{~g}^{-1}\right)$ even with the use of soft templates such as F127. Besides, Jia and co-workers also reported on the successful 
preparation of monolithic PCM with hierarchical porosity via ambient drying with no hydrothermal reaction. ${ }^{31}$

As noted in the literature, however, the SSA can be increased dramatically by activation. ${ }^{32-35}$ For example, Baumann ${ }^{34}$ reported a SSA of $3125 \mathrm{~m}^{2} \mathrm{~g}^{-1}$ via $6 \mathrm{~h}$ of $\mathrm{CO}_{2}$ activation for monolithic PCM at $950{ }^{\circ} \mathrm{C} \mathrm{(vs.} 463 \mathrm{~m}^{2} \mathrm{~g}^{-1}$ before activation), while $2695 \mathrm{~m}^{2} \mathrm{~g}^{-1}$ was obtained via $2 \mathrm{~h}$ of $\mathrm{CO}_{2}$ activation at $1000{ }^{\circ} \mathrm{C}\left(v s .630 \mathrm{~m}^{2} \mathrm{~g}^{-1}\right) \cdot{ }^{33}$ The increase is believed to be due to the micro- and meso-pores introduced by activation. ${ }^{36}$ This suggests that it may be possible to obtain hierarchical porosity via activation, rather than utilizing a soft template. However, a high degree of activation is also known to enlarge the existing micro- or meso-pores, ${ }^{37}$ generating meso- or macro-pores, which could possibly increase flow efficiency but decrease the SSA. Therefore, activation conditions need to be carefully controlled in order to maximize the micro- and mesopores for high SSA and to minimize the macro-pores to prevent an appreciable decrease in the SSA while still having enough to ensure good flow efficiency.

To this end, longer activation time, ${ }^{33}$ higher temperature ${ }^{34}$ and/or higher concentration of activation agents ${ }^{35}$ were employed to obtain higher SSA. This in turn led to higher degrees of activation, but was also accompanied by high burn off ratios $(\sim 80 \%)$, which can be problematic at times. ${ }^{\mathbf{1 0}}$ However, a maximum pore volume was also reported at $\sim 40 \%$ burn off ratio. ${ }^{37} \mathrm{SEM}$ micrographs from these studies show that the discrepancy can be attributed to different morphologies. The former showed monolithic PCM with small pores arising from highly aggregated carbon particles, ${ }^{34}$ requiring a high burn off ratio to obtain not only micro- and meso-pores but also macro- pores for hierarchical porosity via activation. In contrast, the latter used an olive stone with large pores of several microns, ${ }^{38}$ requiring only an introduction of micro- and meso-pores for hierarchical porosity, and thus, low burn off ratio reported. Therefore, the latter approach appears to be more promising in obtaining monolithic PCM with large pores without supercritical drying, and hierarchical porosity can be subsequently achieved via activation.

In this study, therefore, it was attempted to prepare monolithic xerogel PCM with a co-continuous large $(\sim \mu \mathrm{m})$ pore structure via base-catalysed polycondensation reaction. Resorcinol was chosen over phenol because of its better solubility in water, ${ }^{39}$ while $\mathrm{R} / \mathrm{W}(25-45)$ and $\mathrm{R} / \mathrm{C}(1-10 \mathrm{k})$ ratios were varied to obtain the monolith. ${ }^{40}$ Hydrothermal reaction with a Teflon mould was employed to give a co-continuous large pore structure via polymerization-induced spinodal decomposition, as well as a tenacious pore structure to avoid supercritical drying. ${ }^{41-43}$ A soft template was not used to make the process simple and inexpensive, ${ }^{\mathbf{4 4 , 4 5}}$ while micro- and meso-pores were introduced by $\mathrm{CO}_{2}$ activation to afford hierarchical porosity in combination with large pores from spinodal decomposition. ${ }^{36}$ The monolithic carbon xerogels obtained were characterized by SEM and $\mathrm{N}_{2}$ adsorption-desorption measurements.

\section{Experimental}

\section{Materials}

For monolithic carbon xerogels with co-continuous large pores, resorcinol (R, Aldrich 398047, >99\%), formaldehyde (F, Aldrich
252549, 37 wt $\%$ in $\mathrm{H}_{2} \mathrm{O}$ ) and sodium carbonate concentrate (Aldrich 56169, $0.1 \mathrm{M} \mathrm{Na}_{2} \mathrm{CO}_{3}$ ) were used as-received.

\section{Preparation of monolithic RF xerogels via hydrothermal process}

Monolithic RF xerogels were prepared via polycondensation hydrothermal reaction ${ }^{30}$ from resorcinol and formaldehyde with sodium carbonate $\left(\mathrm{Na}_{2} \mathrm{CO}_{3}\right)$ as a catalyst. First, the RF solution was prepared by charging formaldehyde (F) by weight to a glass vial, followed by the addition of distilled water (W, resistivity of $18 \mathrm{M} \Omega \mathrm{cm}$ via Milli-Q Advantage System) and then resorcinol (R).

Loading of $\mathrm{R}$ was varied from $2.5,3.5$ or $4.5 \mathrm{~g}$ to afford $\mathrm{R} / \mathrm{W}=$ 25,35 , or 45 , respectively, while $\mathrm{R} / \mathrm{C}$ ratio (molar) was changed from $1000(1 \mathrm{k}), 2500(2.5 \mathrm{k}), 5000(5 \mathrm{k})$ or $10000(10 \mathrm{k})$ at a fixed $\mathrm{R} / \mathrm{F}$ ratio of 0.5 . These values were chosen based on the model proposed by Scherdel and co-workers to afford monolithic RF gels. ${ }^{41}$ The total amount of water was controlled to $10 \mathrm{ml}$, which included the volume from the $37 \%$ formaldehyde ( $\mathrm{MeOH}$ was considered water). After complete dissolution of $\mathrm{R}$, the mixture poured into a Teflon mould with four holes $(36 \mathrm{~mm}$ in diameter and $40 \mathrm{~mm}$ in depth) and an aluminium top plate to prevent the pressure loss during the reaction. The mould was then placed in an air convection oven at $100{ }^{\circ} \mathrm{C}$ for $6 \mathrm{~h}$. The temperature was selected based on the previous study ${ }^{30}$ to give a co-continuous pore structure via polymerization-induced spinodal decomposition, as well as a tenacious polymer network to avoid supercritical drying. Finally, the RF gels were dried for $42 \mathrm{~h}$ at $60{ }^{\circ} \mathrm{C}$ and for additional $6 \mathrm{~h}$ at $100{ }^{\circ} \mathrm{C}$ to achieve complete drying without the appearance of cracks.

\section{Pyrolysis and activation of monolithic RF xerogels}

$\mathrm{RF}$ xerogels (diameter of $\sim 34 \mathrm{~mm}$ and thickness of $\sim 15 \mathrm{~mm}$ ) were subjected to pyrolysis in a tube furnace (MSTF-1100, Myungsung Eng., Korea). The furnace was heated from RT to $900{ }^{\circ} \mathrm{C}$ at $5^{\circ} \mathrm{C} \mathrm{min}^{-1}$ under $\mathrm{N}_{2}$ flow of $200 \mathrm{sccm}$ and held for $2 \mathrm{~h}$, before cooling it naturally under $\mathrm{N}_{2}$ flow. The carbon gels obtained were cut in half and subjected to activation in the same tube furnace, but at $1000{ }^{\circ} \mathrm{C}$ under $\mathrm{CO}_{2}$ flow of $200 \mathrm{sccm}$ for 2,4 or $6 \mathrm{~h}$. The burn off ratios and crack generation were recorded for comparison. All monolithic carbon xerogels were analysed by SEM (Jeol, JSM-7500F) at $10 \mathrm{keV}$ with carbon coating. Pore characteristics of the monolithic carbon xerogels were measured with an adsorption instrument (ASAP-2010, Micromeritics, USA) using nitrogen at $77 \mathrm{~K}$. Specific surface area (SSA) and pore size distribution were calculated by Brunauer-Emmett-Teller (BET) and Barrett-Joyner-Halenda (BJH) methods, respectively, while the mean pore size was obtained from 4V/SSA. Total pore volumes were calculated from the total single point adsorption of pores less than $300 \mathrm{~nm}$ radius at $P / P_{\mathrm{o}}=0.99$, and micro-pore volumes were obtained via the $t$-plot theory.

\section{Results and discussion}

Preparation of monolithic RF xerogels

As expected from the model by Scherdel and co-workers, ${ }^{\mathbf{4 1}}$ monolithic RF gels were successfully prepared from all 
combination of high $\mathrm{R} / \mathrm{W}(25,35$, and 45$)$ and $\mathrm{R} / \mathrm{C}$ ratios $(1,2.5,5$, and 10k). Subsequent drying for $42 \mathrm{~h}$ at $60^{\circ} \mathrm{C}$ and for additional $6 \mathrm{~h}$ at $100{ }^{\circ} \mathrm{C}$ resulted in disk-shaped RF xerogels without cracks (Fig. S1 $\dagger$ ). As these were dried under ambient conditions, a much longer time was required, but drying at higher temperatures than $60{ }^{\circ} \mathrm{C}$ resulted in the appearance of cracks despite the shorter drying time. The successful preparation of xerogels can be attributed to the hydrothermal reaction using a Teflon mould at $100{ }^{\circ} \mathrm{C},{ }^{30}$ which provided tenacious $\mathrm{RF}$ gels capable of withstanding drying at $60{ }^{\circ} \mathrm{C}$. A small shrinkage upon drying was observed, making it easy to remove the RF xerogel from the mould. Also, the xerogels were rigid enough to prevent breakage by hand, possibly due to good connectivity or particles. ${ }^{46}$

\section{Pyrolysis of monolithic RF xerogels}

When RF xerogels were subjected to pyrolysis, carbon xerogels were generated without a shape change, but a weight loss of $\sim 50 \%$ occurred, which was similar to what was reported in a previous study ${ }^{\mathbf{4 1}}$ and which was supported by TGA results in this study (Fig. S2 $\dagger$ ). The loss was also accompanied by a volume shrinkage of $\sim 55 \%$, which can be compared with $50 \%$ (ref. 6) and $70 \%$ (ref. 46 ) reported in the literature. The difference can be attributed to the different formulations used. Despite such a loss, the carbon xerogels were still hard enough to withstand hand breakage.

The SEM analysis showed that RF xerogels from $\mathrm{R} / \mathrm{W}=45$ exhibited a co-continuous pore structure with interconnected carbon particles, which is clearly observed in $\mathrm{R} / \mathrm{W}=45$ and $\mathrm{R} / \mathrm{C}$ $=10 \mathrm{k}$ (named as $45-10 \mathrm{k}$ ) with a pore size of $2-3 \mu \mathrm{m}$ (Fig. 1). However, there was an increased aggregation of particles as the $\mathrm{R} / \mathrm{C}$ decreased, resulting in a pore structure with aggregated carbon particles, rather than a co-continuous pore structure (45$1 \mathrm{k})$. It should be noted that the co-continuous pore structure observed from 45-10k was similar to that reported by Baumann and co-workers, ${ }^{34}$ which was obtained after carrying out activation for $6 \mathrm{~h}$ at $950{ }^{\circ} \mathrm{C}$ with $\mathrm{CO}_{2}$. But the pore size $(2-3 \mu \mathrm{m})$ observed in our study was much smaller than that observed by Huang and co-workers $(10-20 \mu \mathrm{m}),{ }^{30}$ possibly due to the high R/ $\mathrm{W}$ used in this study. This demonstrated successful preparation of monolithic carbon xerogels with a co-continuous large pore structure from resorcinol and formaldehyde via hydrothermal polycondensation reaction.

The gels from $\mathrm{R} / \mathrm{W}=35$ exhibited a pore structure with highly aggregated large carbon particles $(\sim 2 \mu \mathrm{m}$ in diameter $)$ for all $\mathrm{R} / \mathrm{C}$ ratios, rather than an interconnected co-continuous pore structure (Fig. S3†). A similar pore structure was also observed from $\mathrm{R} / \mathrm{W}=25$, but with a larger particle size $(\sim 3 \mu \mathrm{m})$, again irrespective of the $\mathrm{R} / \mathrm{C}$ ratio (Fig. $\mathrm{S} 4 \dagger$ ). This demonstrated that the particle size increased with decreasing $\mathrm{R} / \mathrm{W}$, as reported previously. ${ }^{5,6}$ The effect of $\mathrm{R} / \mathrm{C}$ ratio on the particle size proved to be negligible in $\mathrm{R} / \mathrm{W}=25$ and 35 gels, but the effect was clearly observed in $\mathrm{R} / \mathrm{W}=45$ gels. This demonstrated that a cocontinuous pore structure with interconnected particles can be obtained only if the conditions are optimal, even if polymerization-induced spinodal decomposition is obtained via polycondensation hydrothermal reaction.

A $\mathrm{N}_{2}$ adsorption-desorption study on the $\mathrm{R} / \mathrm{W}=45$ gels, whose co-continuous pore structure was verified, showed either Type I (45-10k, and 45-5k) or Type IV isotherms (45-1k and 45$2.5 \mathrm{k}$ ), as shown in Fig. 2a. Type I isotherms can be attributed to mostly micro-pores, while Type IV isotherms are attributed to the presence of some number of meso- and macro-pores. This was supported by the pore size distribution measurements (Fig. 2b), which showed a negligible number of meso- and macro-pores for $45-10 \mathrm{k}$ and $45-5 \mathrm{k}$, but an appreciable number for 45-2.5k. However, 45-1k exhibited a much higher number of meso-pores but a lower number of macro-pores than $45-2.5 \mathrm{k}$ (Fig. 2b). By correlating these with the SEM results (Fig. 1), it can be proposed that as the $\mathrm{R} / \mathrm{C}$ ratio decreases, the particle size decreases along with increased aggregation, resulting in a larger number of smaller pores such as meso and macro-pores. The decreased number of macro-pores for $45-1 \mathrm{k}$ can be attributed to very small particles that can only form meso-pores upon aggregation. This was also supported by the increased mean pore size with lower $\mathrm{R} / \mathrm{C}$ ratios (Table 1 ). In addition, the peak at 3-4 $\mathrm{nm}$ is believed to be due to the tensile strength effect caused by the ink-bottle or cylinder-type pores. ${ }^{47}$

Furthermore, the calculated total and micro-pore volumes also supported this hypothesis (Table 1), showing an increased total pore volume with lower $\mathrm{R} / \mathrm{C}$ ratios, but a similar micropore volume, irrespective of $\mathrm{R} / \mathrm{C}$ ratios. The former can be again attributed to the increased meso- and macro-pores due to the decreased particle size and increased aggregation. The latter can be explained by the same amount of resorcinol and formaldehyde used for RF gels, despite their dissimilar morphologies in the SEM, resulting in the same or similar volume and possibly generating a similar amount of micro-pores upon pyrolysis. ${ }^{46}$ This was supported by the $50 \%$ weight loss upon pyrolysis, irrespective of the $\mathrm{R} / \mathrm{C}$ ratios, and by the results reported by Yamamoto and co-workers. ${ }^{6}$ As expected, similar SSAs of $673,682,696$, and 656 were obtained for $45-1 \mathrm{k}, 45-2.5 \mathrm{k}, 45-5 \mathrm{k}$ and $45-10 \mathrm{k}$, respectively.
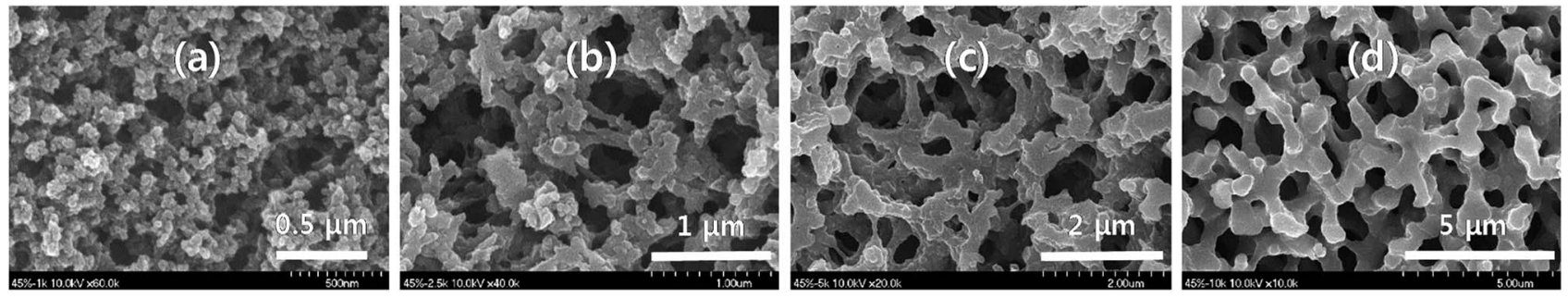

Fig. 1 SEM of RF-based monolithic carbon xerogels, (a) 45-1k, (b) 45-2.5k, (c) 45-5k and (d) 45-10k. 

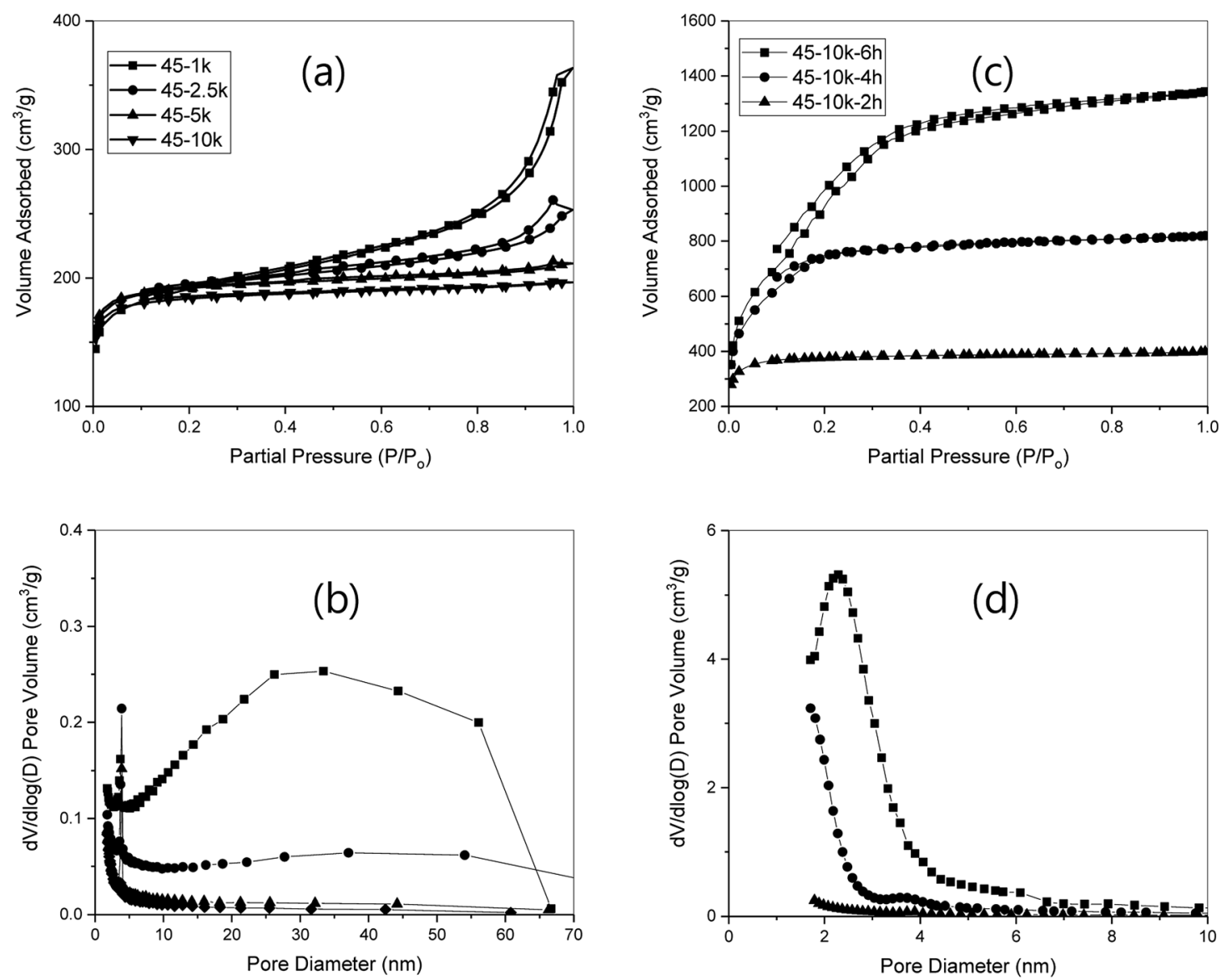

Fig. $2 \mathrm{~N}_{2}$ isotherms of monolithic carbon xerogels from 45-1, 2.5, 5, or 10k (a) and their pore size distribution, (b) isotherms from 45-10k-2 $\mathrm{h}, 4 \mathrm{~h}$, or $6 \mathrm{~h} \mathrm{CO} 2$ activation (c) and their pore size distribution (d).

\section{$\mathrm{CO}_{2}$ activation of carbon xerogels}

Given that the SSA values of monolithic carbon xerogels from $\mathrm{R} /$ $\mathrm{W}=45$ were very high, activation was carried out under $\mathrm{CO}_{2}$ flow. As expected from a previous study, ${ }^{34}$ the longer activation time resulted in higher burn off ratios; for example, 31, 56, or $81 \%$ with 2,4 or $6 \mathrm{~h}$ of activation for $45-10 \mathrm{k}$ (Table 1 ). Similar results were obtained from other samples $(45-1 \mathrm{k}, 45-2.5 \mathrm{k}$, or $45-$ $5 \mathrm{k}$ ), but slightly increased values were observed with lower $\mathrm{R} / \mathrm{C}$ ratios (Table $\mathrm{S} 1 \dagger$ ). Tsuchiya, ${ }^{33}$ however, reported increased burn off ratios with higher $\mathrm{R} / \mathrm{C}$ ratios, which may be explained by the lower catalyst concentration $(\mathrm{R} / \mathrm{C}=1-10 \mathrm{k})$ and higher reaction temperature $\left(100{ }^{\circ} \mathrm{C}\right)$ used in the study.
Some samples also exhibited a crack or cracks, especially with lower R/C ratios and longer activation time (Table $\mathrm{S} 1 \dagger$ ). As noted, large cracks can be correlated to the high burn off ratio. However, the gels from 45-10k did not exhibit any cracks despite the high burn off ratio (as high as 81\%) and maintained the monolithic structure, while a slight size reduction was observed in the gels with $6 \mathrm{~h}$ of activation. Nevertheless, these gels (4510k) still provided sufficiently high stiffness even after $6 \mathrm{~h}$ of activation to withstand hand breakage. Therefore, these gels were subjected to $\mathrm{N}_{2}$ adsorption-desorption measurements, which provided SSAs of 1306, 2463 and $3311 \mathrm{~m}^{2} \mathrm{~g}^{-1}$ for $45-10 \mathrm{k}-$ $2 \mathrm{~h}, 45-10 \mathrm{k}-4 \mathrm{~h}$ and $45-10 \mathrm{k}-6 \mathrm{~h}$, respectively. Given that the

Table 1 Characteristics of monolithic carbon xerogels without and with activation

\begin{tabular}{|c|c|c|c|c|c|}
\hline & $S^{a}\left(\mathrm{~m}^{2} \mathrm{~g}^{-1}\right)$ & $V_{\text {total }}^{b}\left(\mathrm{~cm}^{3} \mathrm{~g}^{-1}\right)$ & $V_{\text {micro }}{ }^{c}\left(\mathrm{~cm}^{3} \mathrm{~g}^{-1}\right)$ & $D_{\mathrm{p}}^{d}(\mathrm{~nm})$ & $\operatorname{BOR}^{e}(\%)$ \\
\hline $45-1 \mathrm{k}$ & 663 & 0.516 & 0.221 & 2.91 & - \\
\hline $45-2.5 \mathrm{k}$ & 672 & 0.339 & 0.237 & 1.99 & - \\
\hline $45-5 \mathrm{k}$ & 686 & 0.291 & 0.256 & 1.62 & - \\
\hline $45-10 \mathrm{k}$ & 656 & 0.266 & 0.246 & 1.56 & - \\
\hline $45-10 \mathrm{k}-2 \mathrm{~h}$ & 1306 & 0.511 & 0.493 & 1.56 & 31 \\
\hline $45-10 \mathrm{k}-4 \mathrm{~h}$ & 2463 & 1.049 & 0.910 & 1.70 & 56 \\
\hline $45-10 \mathrm{k}-6 \mathrm{~h}$ & 3311 & 1.719 & 1.359 & 2.07 & 81 \\
\hline
\end{tabular}

${ }^{a}$ Specific surface area. ${ }^{b}$ Total pore volume. ${ }^{c}$ Micro pore volume. ${ }^{d}$ Mean pore size. ${ }^{e}$ Burn off ratio from weight loss. 

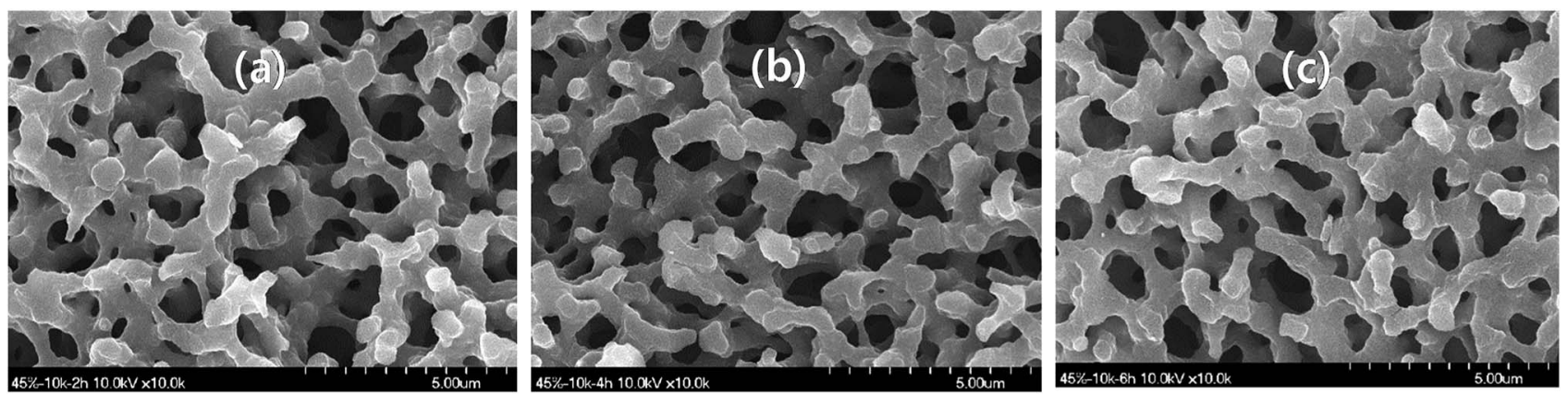

Fig. 3 SEM of activated carbon xerogels from 45-10k for (a) $2 \mathrm{~h}$, (b) $4 \mathrm{~h}$ or (c) $6 \mathrm{~h}$ activation.

carbon xerogels have a SSA of $\sim 650 \mathrm{~m}^{2} \mathrm{~g}^{-1}$ (before activation), this is a dramatic increase, as expected from earlier studies. ${ }^{34,43}$ Type I isotherms were observed from all samples, indicating a presence of mostly micro-pores (Fig. 2c), but adsorption increased highly with longer activation time, demonstrating the introduction of micro-pores, as well as meso-pores, via activation. This was supported by the pore size distribution (Fig. 2d), which showed an increased pore diameter from micro- to mesopores with longer activation time. It was also supported by the increased mean pore size with longer activation time (Table 1). In addition, a higher meso-pore volume was obtained with longer activation time. This corresponded well with the aim of this study, which was to obtain a hierarchical pore structure by combining these micro- and meso-pores with large pores from spinodal decomposition. Unfortunately, the micro-pore volume was $79 \%$ and higher than what was expected, despite the very high degree of activation or very high burn off ratio (81\%). This can be correlated to the study by Tsuchiya ${ }^{33}$ who reported that introduction of meso- or macro-pores via activation is proportionally increased to the number of those already in the gel.

Therefore, the isotherms of the gels from 45-2.5k, which already contained micro-, meso- and macro-pores, were obtained. The results showed SSAs of 1468,2650 and 3163 for 452.5k-2 h, 45-2.5k-4 h, and 45-2.5k-6 h, respectively, which were similar to the values obtained from $45-10 \mathrm{k}$. However, these exhibited a combination of Type I and Type IV isotherms (Fig. S5a $\dagger$ ), rather than a Type I isotherm, indicating the presence of meso- as well as macro-pores. Also, a small increase in adsorption was noted at high $P / P_{\mathrm{o}}$, which increased with longer activation time, indicating more macro-pores upon longer activation time. This suggests a much greater number of mesoand macro-pores after activation, which was also supported by the pore size distribution (Fig. S5b $\dagger$ ). These results can again be correlated to the study by Tsuchiya, ${ }^{33}$ as discussed in the previous paragraph. Thus, the gels from $45-2.5 \mathrm{k}$ appears to be better than those from $45-10 \mathrm{k}$ in terms of number of meso- and macro-pores observed, but the former exhibited cracks upon activation even at $2 \mathrm{~h}$ and was no longer a monolith.

The xerogels from 45-10k after activation showed a very similar morphology to that before activation despite the high burn off ratio (Fig. 3), being similar to the results from earlier study. ${ }^{7}$ This indicates no appreciable external burning of the skeleton, which is contrary to what was expected from the high burn off ratio. Thus, high burn off ratio upon activation can be attributed to introduction of micro-and meso-pores, as well as their enlargement to meso- and macro-pores. This may be the reason for the very high SSA after activation.

\section{Conclusion}

Monolithic carbon xerogels with hierarchical porosity were successfully prepared via base-catalysed hydrothermal polycondensation reaction from resorcinol and formaldehyde, followed by pyrolysis and activation, without a template and supercritical drying. This success can be attributed to (1) high R/ $\mathrm{W}(45)$ and $\mathrm{R} / \mathrm{C}(1-10 \mathrm{k})$ ratios leading to a monolithic structure, (2) hydrothermal reaction providing a co-continuous large-pore structure via spinodal decomposition, as well as tenacious RF gels to avoid supercritical drying, and (3) introduction of microand meso-pores via activation to form hierarchical porosity in combination with large pores via spinodal decomposition. Upon pyrolysis, all xerogels showed $\sim 50 \%$ weight loss and $\sim 55 \%$ volume shrinkage, but $\mathrm{CO}_{2}$ activation at $1000^{\circ} \mathrm{C}$ resulted in a large weight loss and the presence of cracks, which became severe with longer activation time and/or lower $\mathrm{R} / \mathrm{C}$ ratio. However, the gels from 45-10k showed no cracks and high stiffness, and provided SSAs of 1,306, 2463 and $3311 \mathrm{~m}^{2} \mathrm{~g}^{-1}$ for 45-10k-2 h, 45-10k-4 h and 45-10k-6 h, respectively. These values were much higher than $\sim 650 \mathrm{~m}^{2} \mathrm{~g}^{-1}$ obtained from carbon xerogels (before activation) and can be attributed to micro- and meso-pores introduced by activation, which in turn led to the formation of hierarchical porosity in combination with large pores from spinodal decomposition.

\section{Conflicts of interest}

There are no conflicts to declare.

\section{Acknowledgements}

This research was supported by the National Strategic ProjectFine Particle of the National Research Foundation of Korea (NRF) funded by the Ministry of Science and ICT (MSIT), the Ministry of Environment (ME), and the Ministry of Health and Welfare (MOHW)(2017M3D8A1091937) and also by Gwangju Institute of Science and Technology (GIST) through the 2018 Grant of GIST Research Institute. 


\section{Notes and references}

1 R. W. Pekala, J. Mater. Sci., 1989, 24, 3221.

2 X. Lu, R. Caps, J. Fricke, C. T. Alviso and R. W. Pekala, J. NonCryst. Solids, 1995, 188, 226.

3 R. W. Pekala, C. T. Alviso, F. M. Kong and S. S. Hulsey, J. NonCryst. Solids, 1992, 145, 90.

4 R. Saliger, V. Bock, R. Petricevic, T. Tilloston, S. Geis and J. Fricke, J. Non-Cryst. Solids, 1997, 221, 144.

5 H. Tamon, H. Ishizaka, T. Araki and M. Okazaki, Carbon, 1998, 36, 1257.

6 Y. Yamamoto, T. Nishimura, T. Suzuki and H. Tamon, J. NonCryst. Solids, 2001, 288, 46.

7 A. Léonard, S. Blacher, M. Crine and W. Jomaa, J. Non-Cryst. Solids, 2008, 354, 831.

8 Y. Liu, J. Luo, C. Helleu, M. Behr, H. Ba, T. Romero, A. Hébraud, G. Schlatter, O. Ersen, D. S. Su and C. PhamHuu, J. Mater. Chem. A, 2017, 5, 2151.

9 H. Obersacher and C. G. Huber, TrAC, Trends Anal. Chem., 2002, 21, 166.

10 Y. Zhai, Y. Dou, D. Zhao, P. F. Fulvio, R. T. Mayes and S. Dai, Adv. Mater., 2011, 23, 4828.

11 I. Matos, M. Bernardo and I. Fonseca, Catal. Today, 2017, 285, 194.

12 A. H. Lu, G. P. Jao and X. Q. Zhang, Porous carbons for carbon dioxide capture in Porous Materials for Carbon Capture, Green Chemistry and Sustainable Technology, Springer-Verlag, Berlin Heidelberg, 2014.

13 B. S. Girgis, A. A. Attia and N. A. Fathy, Desalination, 2011, 265, 169.

14 N. A. Fathy, M. S. Rizk and R. M. S. Awad, J. Anal. Appl. Pyrolysis, 2016, 119, 60.

15 S. Dutta, A. Bhaumik and K. C.-W. Wu, Energy Environ. Sci., 2014, 7, 3574.

16 X.-Y. Yang, L.-H. Chen, Y. Li, J. C. Rooke, C. Sanchezc and B.-L. Su, Chem. Soc. Rev., 2017, 46, 481.

17 Y. Deng, C. Liu, T. Yu, F. Liu, F. Zhang, Y. Wan, L. Zhang, C. Wang, B. Tu, P. A. Webley, H. Wang and D. Zhao, Chem. Mater., 2007, 19, 3271.

18 Y. R. Liang, D. Wu and R. Fu, Langmuir, 2009, 25, 7783.

19 Y. Jiao, S. W. Cho, S. Lee, S. H. Kim, S. Y. Jeon, K. Hur, S. M. Yoon, M.-W. Moon and A. Wang, Adv. Eng. Mater., 2018, 20, 1700608.

20 S. Valkama, A. Nykänen, H. Kosonen, R. Ramani, F. Tuomisto, P. Engelhardt, G. Brinke, O. Ikkala and J. Ruokolainen, Adv. Funct. Mater., 2007, 17, 183.

21 G. P. Hao, W. C. Li, S. Wang, G. H. Wang, L. Qi and A. H. Lu, Carbon, 2011, 49, 3762.
22 D. Carriazo, M. C. Gutiérrez, M. L. Ferrer and F. del Monte, Chem. Mater., 2010, 22, 6146.

23 M. C. Gutierrez, F. Pico, F. Rubio, J. M. Amarilla, F. J. Palomares, M. L. Ferrer, F. del Monte and J. M. Rojo, J. Mater. Chem., 2009, 19, 1236.

24 C. Liang and S. Dai, Chem. Mater., 2009, 21, 2115.

25 C. Xue, B. Tu and D. Zhao, Nano Res., 2009, 2, 242.

26 G. Hasegawa, K. Kanamori, T. Kiyomura, H. Kurata, T. Abe and K. Nakanish, Chem. Mater., 2016, 28, 3944.

27 A. Feinle, M. S. Elsaeser and N. Huesing, Chem. Soc. Rev., 2016, 45, 3377.

28 G. Hasegawa, M. Aoki, K. Kanamori, K. Nakanishi, T. Hanada and K. Tadanaga, J. Mater. Chem., 2011, 21, 2060.

29 S. Xu, J. Li, G. Qiao, H. Wang and T. Lu, Carbon, 2009, 47, 2103.

30 Y. Huang, H. Cai, D. Feng, D. Gu, Y. Deng, B. Tu, H. Wang, P. A. Webley and D. Zhao, Chem. Commun., 2008, 2641.

31 X. Jia, B. Dai, Z. Zhu, J. Wang, W. Qiao, D. Long and L. Ling, Carbon, 2016, 108, 551.

32 J. Xu, A. Wang and T. Zhang, Carbon, 2012, 50, 1807.

33 T. Tsuchiya, T. Mori, S. Iwamura, I. Ogino and S. R. Mukai, Carbon, 2014, 76, 240.

34 T. F. Baumann, M. A. Worsley, T. Y.-J. Han and J. H. Satcher, J. Non-Cryst. Solids, 2008, 354, 3513.

35 A. D. Roberts, J.-S. M. Lee, S. Y. Wong, X. Li and H. Zhang, J. Mater. Chem. A, 2017, 5, 2811.

36 W. M. Qiao, S. H. Yoon and I. Michida, Energy Fuels, 2006, 20, 1680.

37 M. Molina-Sabio, M. T. Gonzalez, F. Rodriguez-Reinoso and A. Sepúlveda-Escribano, Carbon, 1996, 34, 505.

38 T. M. Alslaibi, I. Abustan, M. A. Ahmad and A. A. Foul, AIChE J., 2014, 60, 237.

39 S. A. Al-Muhtaseb and J. A. Ritter, Adv. Mater., 2003, 15, 101. 40 C. Lin and J. A. Ritter, Carbon, 2000, 38, 849.

41 C. Scherdel, T. Scherb and G. Reichenauer, Carbon, 2009, 47, 2244.

42 R. Petricevic, M. Glora and J. Fricke, Carbon, 2001, 39, 857.

43 H. Zhou, S. Xu, H. Su, M. Wang, W. Qiao, L. Ling and D. Long, Chem. Commun., 2013, 49, 3763.

44 M. Serwar, U. A. Rana, H. M. Siddiqi, S. U. Khan, F. A. Ahmed Ali, A. Al-Fatesh, A. Adomkevicius, J. A. Coca-Clemente, L. Cabo-Fernandez, F. Braga and L. J. Hardwick, RSC Adv., 2017, 7, 54626.

45 H. Sun, W. He, C. Zong and L. Lu, ACS Appl. Mater. Interfaces, 2013, 5, 2261.

46 R. W. Pekala, C. T. Alviso, X. Lu, J. Gross and J. Fricke, J. NonCryst. Solids, 1995, 188, 34.

47 J. C. Groen, L. A. A. Peffer and J. Perez-Ramirez, Microporous Mesoporous Mater., 2003, 60, 1. 